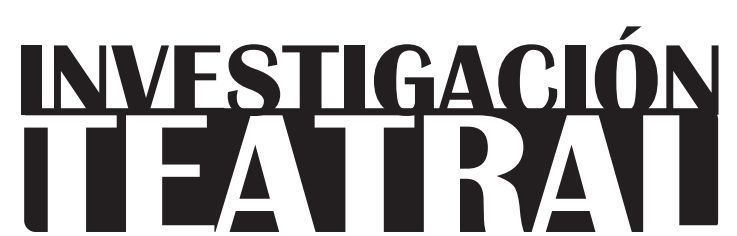

Revista de artes escénicas y performatividad

Vol. 10, Núm. 15

abril-septiembre 2019

Segunda época

ISSN impreso: 1665-8728

ISSN electrónico: 2594-0953

Universidad Veracruzana

\title{
El diálogo afectivo con la tradición en el teatro chileno reciente: una lectura de Neva, de Guillermo Calderón
}

\author{
Javiera Larraín George*
}

\footnotetext{
* Pontificia Universidad Católica de Chile, Chile. e-mail: javiera.larraing@gmail.com
}

Recibido: 26 de noviembre de 2018

Aceptado: 27 de febrero de 2019 


\title{
El diálogo afectivo con la tradición en el teatro chileno reciente: una lectura de Neva, de Guillermo Calderón
}

\section{Resumen:}

El presente artículo pretende establecer una lectura acuciosa de la obra Neva, del destacado dramaturgo y director Guillermo Calderón, a través de su trabajo en torno a la metateatralidad y el uso de la voz natural. Neva, en consecuencia, articula los principios básicos de aquellos elementos que son característicos de gran parte de la producción del autor. Asimismo, a partir del análisis de esta obra se persigue entender la filiación entre el trabajo de Calderón y la tradición chilena teatral que éste hereda, influida por una fuerte presencia del realismo naturalista.

Palabras clave: Guillermo Calderón, teatro chileno, metateatralidad, realismo, voz, Chile.

\section{An Affective Dialogue with Tradition in Recent Chilean Theater: A Reading of Neva, by Guillermo Calderón}

\begin{abstract}
:
This article seeks to establish a thorough reading of Neva, by prominent Chilean playwright and director Guilermo Calderón, using both his work on metatheatricality and the natural voice. The reading will therefore articulate the basic principles of the elements that characterize the author's entire production. From the analysis of this piece, we seek to understand the relationship between Calderon's work and the Chilean theatrical tradition that he inherits, influenced as it is by a strong presence of naturalist realism.
\end{abstract}

Keywords: Guillermo Calderón, chilean theater, metatheatricality, realism, voice, Chile. 


\section{El diálogo afectivo con la tradición en el teatro chileno reciente: una lectura de Neva, de Guillermo Calderón}

El trabajo cobró así su ritmo, con excepción del papel de Masha, que habia tocado a la actriz Knipper. De esto se ocupó Vladimir Ivánovich, y pronto también a ella se le reveló algo en el alma, y todo comenzó a marchar de las mil maravillas.

El pobre Antón Pávlovich no pudo esperar hasta la representación. Tuvo que irse al extranjero, bajo el pretexto de que su salud había empeorado; aunque yo sospecho que hubo otra causa más: la preocupación por la pieza y su destino ulterior en las tablas. Esta suposición se vería confirmada por la circunstancia de que ni siquiera nos dejaba la dirección adonde podríamos dirigirnos para informarle sobre los resultados del estreno. Ni siquiera la misma Knipper la conocía, a pesar de que ella...

Konstantín Stanislavski, Mi vida en el arte (1925)

\section{Breve panorama sobre la escena chilena del nuevo milenio} a primera década del siglo Xxi se caracteriza por un reajuste en los modelos teatrales de la escena nacional en Chile. Los directores de esta nueva generación, ${ }^{1}$ junto con sus compañías, ya no buscan, primordialmente, "montar" textos, sino que realizan

1 Para las pretensiones del presente artículo, los autores circunscritos en la generación de Guillermo Calderón se inscriben -según la propuesta de Cedomil Goic- en la generación del 2002, ya que éstos nacie- 
un trabajo de investigación escénica que surge desde la praxis y las inquietudes direccionales y actorales del grupo de trabajo a partir de los propios procesos de ensayos. En palabras de María de la Luz Hurtado, esta generación destaca por sus "Desplazamiento[s] e hibridaciones, entonces, contaminaciones mutuas entre arte y cultura en las cuales los academicismos son transgredidos como programa base. La 'pieza bien hecha', el 'montaje bien realizado' como interpretación fiel a una supuesta voluntad autoral originaria se bate en retirada en el teatro" (Teatro chileno 18). Los directores teatrales de la escena chilena del nuevo milenio ${ }^{2}$ ponen en juego una serie de lenguajes eclécticos, logrando hacer dialogar el discurso de la tradición con aportes nuevos, acordes a las recientes tecnologías que aportan los formatos audiovisuales, sonoros, lumínicos, entre otros.

La figura de Guillermo Calderón $(1971)^{3}$ conforma, precisamente, parte de este eje generacional; comienza su trabajo con la Compañía Teatro en Blanco, para después continuar

ron entre 1965 y 1979. Si bien la propuesta de fechas fronterizas de Goic puede ser puesta en jaque en relación a sus supuestos positivistas y a su centralización en una generación de dramaturgos y no necesariamente de directores, su ordenamiento temporal es útil en el sentido que da cuenta de la orfandad crítica de los teatristas surgidos en las últimas tres décadas. Para Goic, habría cinco generaciones de autores teatrales chilenos en los últimos cien años: 1927 (superrealistas), 1942 (neorrealistas), 1957 (irrealista), 1972 (novísimos), además de 1987 y 2002. Hasta la fecha, no existen estudios que, por una parte, puedan dar cuenta de manera sintomática de los rasgos distintivos de estos dos últimos grupos y que, por otra parte, problematicen las redes rizomáticas de entramados relacionales entre las generaciones de 1987, de 2002 y aquella que actualmente le seguiría -correspondiente a autores nacidos a partir de 1980-. Ambos aspectos quedan excluidos de las pretensiones del estudio de Goic, siendo que son problemáticas sumamente necesarias al momento de abordar las prácticas teatrales locales actuales en su total dimensión (Historia y crítica de la literatura hispanoamericana 535-538).

Dentro de esta camada de noveles directores destaca el hecho que muchos de ellos circunscriben sus primeros pasos alrededor de una compañía específica - en algunos casos disueltas en la actualidad- con la que comienzan a formar su propia metodología de trabajo; tal es el caso de figuras como: Ana Harcha Cortés (1976) y Francisca Bernardi (1975), quienes fundan la Compañía Niños Prodigio; Alexis Moreno (1978) y Alexandra Von Hummel (1975), que conforman el Teatro La María (1996); Manuela Infante (1980), fundadora de Teatro de Chile; Luis Ureta (1967), con Teatro La Puerta (1991), y Martín Erazo (1973), con la Compañía La Patogallina (1996), sólo por nombrar algunos casos de compañías teatrales chilenas de los últimos 15 años y que, hasta el día de hoy, algunas de ellas, como sus directores, se encuentran activos en un constante aporte de nuevas obras a la escena nacional. En el marco de este panorama, cabe rescatar que, si bien todos estos directores conforman parte de una misma generación, que según Cristián Opazo, reconocen un teatro nacional cuyo fundamento -o al menos parte de éste- se reconoce en la evanescencia de todo rasgo de realidad, de verdad, de ficción y de impostura (Clase, de Guillermo Calderón 17).

3 Nacido en Santiago, en 1971, su juventud se encuentra marcada por los últimos años de dictadura en Chile. Estudia Teatro en la Universidad de Chile (1989-1993); posteriormente, realiza estudios de especialización en el extranjero: primero, en el Actor's Studio, en Nueva York, E.U., que no continuó por no 
INVESTIGACIÓNTEATRAL

Revista de artes escénicas y performatividad

Vol. 10, Núm. 15

abril-septiembre 2019
El diálogo afectivo con la tradición

en el teatro chileno reciente

Javiera Larraín George

con la Compañía La Reina de Conchalí y otros colectivos. Él forma parte de esta nueva generación de directores que "va constituyendo autorías con personalidad propia no necesariamente mimetizadas con los modelos del centro" (Hurtado, Prólogo 18). Las propuestas de dirección de Calderón ${ }^{4}$ y de su generación descansan, en parte, en la polémica existente entre cuerpo, texto y representación, en donde los ejes de realidad parecerían estar constantemente en jaque desde el constructo de lo (meta)teatral, poniendo, así, "en evidencia la cualidad dual de lo teatral y de la escena, reflexionando de este modo a la par sobre la relación entre realidad y representación, núcleo de lo teatral (y de la vida en tanto lugar de la performance)" (44).

Las preocupaciones autorales ahora, en consecuencia, son otras. Si bien, durante los años 80 y 90, la dirección de la escena chilena buscaba establecer un nuevo estado de sí misma tras la dictadura, a principios del año 2000 las prácticas escénicas parecieron volcarse hacia una búsqueda por el entendimiento de su propia teatralidad. Las prácticas teatrales de comienzos de 2000 se configuraron desde una repolitización de la escena, heredera de las prácticas transformadoras de mediados de los años $80 .^{5}$ En términos de Villegas:

El teatro político no ha desaparecido, aunque sí ha cambiado el mensaje y el modo de comunicación del mismo [...] La diferencia clave con el período anterior radica en

sentirse tan a gusto con las lógicas de actuación stanislavskianas, lo cual lo lleva a profundizar, en segunda instancia, en el teatro físico en la Scuola Dell'Arte en California, E.U., y en la Scuola Internazionale dell'Attore Comico, en Italia. Además, cursó un Máster en Artes Liberales con mención en Cine en la City University of New York, E.U.

4 Permítaseme una precisión metodológica: el presente artículo no busca instalar un análisis de la obra total de Calderón, sino más bien problematizar los ejes fundamentales de la primera parte de su poética, la cual está constituida -desde mi perspectiva crítica- por la tríada compuesta por Neva (2006), Diciembre (2008) y Clase (2008). En todos estos montajes, Calderón articula una relectura -según indican Oyarzún y Opazo- de la tradición clásica del drama moderno (21). Es así que, a través de este gesto, busca cuestionar el teatro en contextos de crisis (revolución civil, guerras y marchas estudiantiles). Para ello, se atiene a un uso minimalista de los recursos materiales del espacio escenográfico, para poner el acento en el trabajo actoral. Lo anterior se diferencia de sus siguientes trabajos (Villa + Discurso, 2010; Escuela, 2013, y Mateluna, 2016) que tienen un foco más centrado en la exposición de un teatro de corte documental -incluso, a ratos, testimonial-; y que buscan alejarse de una lógica de actuación teatral por parte de los actores, transitando hacia un estilo interpretativo más cinematográfico (Larraín, Hacia una poética 228-232).

Directores como Andrés Pérez, Ramón Griffero, Alfredo Castro, Rodrigo Pérez y grupos como La Troppa o Teatro del Silencio transformarán el panorama de la escena chilena a partir de la segunda mitad de la década de los años 80. A partir de ellos se establecerán distintas filiaciones y herencias con las generaciones venideras. 
que el mensaje no suele ser tan directo y los códigos teatrales empleados enfatizan una mayor complejidad estructural y participación del espectador en la decodificación del mensaje. El discurso teatral en esta época incorpora la parodia, la ironía, la metateatralidad como recursos recurrentes que contribuyen, con frecuencia, a la ambigüedad del mensaje (216).

Dicha ambigüedad no se enmarca en la falta de toma de partido y perspectiva ideológica por parte de los autores de la escena teatral posmoderna, sino, más bien, en la necesidad de instalar un panorama político que se encuentra dominado por el escepticismo, con el fin de atestiguar, al mismo tiempo, una voluntad de reminiscencia. Para Avelar, esta voluntad atestigua un llamado de atención del presente a todo aquello que no se logró en el pasado y permea una mirada escéptica del propio presente, al ser producto de una catástrofe del pasado (286).

En este contexto, atravesado por una desconfianza hacia los proyectos político-democráticos, Calderón configura una neo-irrupción de lo real, sin olvidar las alteridades friccionales entre lo real y la ficción, ejes centrales de estas nuevas propuestas escénicas, puesto que el gran aporte del autor consiste en retomar un código tradicional y clásico -el realista- para hacerlo irrumpir en la escena chilena actual, resignificándolo y dotándolo de un nuevo sentido desde el punto de vista:

de la generación de autores y directores teatrales en la que Calderón se inscribe con una voz muy propia, lo vanguardista sería hoy en día montar en Chile obras de Brecht, por ejemplo, intervenidas por la opinión de quienes las escriben y/o dirigen. Es curioso que un clásico del teatro mundial pueda operar como elemento transgresor en un momento puntual (Lagos, Neva: El río 17).

De ahí que pueda entenderse su neo-irrupción de lo real como un acto de vanguardia y subversión escénica. Calderón homenajea la tradición en sus primeros montajes, pero no desde un lugar condescendiente, sino críticamente interpelativo en su exploración de las paradojas - muchas de ellas absurdas - entre el teatro y la vida. Así, para Hurtado, "pareciera que las utopías no han caído definitivamente en el teatro chileno, y que el relativismo postmodernista sea su única y desencantada visión de mundo" (Prólogo 47).

En este panorama de producción se enmarca el trabajo ${ }^{6}$ de Guillermo Calderón. La crítica chilena e internacional han señalado, casi por unanimidad, que es uno de los autores más

6 La obra de Guillermo Calderón es vasta y prolífica, ya no sólo en Chile, sino en todo el mundo. Ha sido invitado para escribir y dirigir en prestigiosos teatros dentro del mundo: Düsseldorfer Schauspielhaus, Theater Basel, HAU Hebbel am Ufer, el Royal Court Theatre, Center Theatre Group, y el Public Theatre en 
importantes de las últimas décadas dentro de la escena nacional chilena (Labra, Ibacache, Bahamondes, Letelier, Oyarzún y Lagos) y la prensa internacional ha alabado sus puestas en escena en el extranjero (The Guardian, The New Yorker, The Washington Post, El Pais, Clarín). De la misma forma, en el mundo académico es posible encontrar no poco -aunque tampoco bastante- material de estudio sobre el autor, sobre todo artículos y tesis de pregrado y posgrado en alguna de sus obras. La mayoría de estas revisiones -sean prensa, crítica especializada o estudios académicos - destacan el papel predominante de la palabra dentro de la construcción de sus piezas que, según Juan Andrés Piña, en Calderón "la envolvente o incluso apabullante marea verbal alcanza por momentos una cima poética; en otros casos primará la fuerza ideológica de quien expone un argumento, su capacidad de representación de un desgarro íntimo, el soliloquio de alguien extraviado en el dolor y la soledad o, también, el relato de una historia que un personaje narra a los demás" (170-171). Por su parte, Carola Oyarzún enfatiza que "Calderón se instala en nuestro campo teatral como una de las figuras más destacadas. Su dedicada relectura de textos clásicos, sumada a su constante preocupación por las coyunturas históricas pasadas (guerras, revoluciones y revueltas callejeras) y presentes hablan, sin duda, de una dramaturgia/dirección que cuestiona el sentido del teatro en contextos dominados por la crisis" (305). Mientras que María de la Luz Hurtado señala que lo metateatral cruza su obra y "se constituye en la indagación en torno a las claves [...] de la memoria emotiva y física de los actores: de su vida personal, de lo vivido, sentido, observado, experimentado en carne propia, como fuente y correlato de la construcción de un personaje 'real', 'creíble,' 'vivo', afectiva, social e históricamente fundado" (Teatro chileno 45).

\section{Los albores de una poética al clamor de la revolución bolchevique}

Neva no es sólo el nombre de uno de los ríos más importantes de Rusia, que atraviesa la ciudad de San Petersburgo. También es el nombre de la primera obra escrita y dirigida por Guillermo Calderón, quien la estrenó en 2006, junto a la Compañía Teatro en el Blanco. La

la ciudad de Nueva York, donde también dirigió Neva con actores norteamericanos (The Public, Nueva York, 2012), al igual que Villa (Play Co, Nueva York, 2017). Las obras de Calderón han recorrido extensamente el mundo, destacando: Uruguay, Brasil, Bolivia, Canadá, Portugal, México, Cuba, Colombia, Escocia, Grecia, Estados Unidos, Francia, Italia, Inglaterra y, por supuesto, Chile. Participando, asimismo, en importantes festivales: Festival Internacional de Teatro de Buenos Aires (FIBA), Festival Fringe de Edimburgo, Festival de Artes Escénicas de Seúl, Festival Chekhov en Moscú, Festival de Teatro Iberoamericano en España, TeatroStageFest, Festival de Teatro de Viena, Festival Mundial de Teatro en Bruselas, Festival Bajo el Radar del Teatro Público, entre otros. 
anécdota se sitúa en 1905, en el preludio de la Revolución Rusa, en donde dos actrices y un actor -Olga Knipper, viuda del dramaturgo Antón Chejov; Masha, una actriz de filiaciones obrero-proletarias, y Aleko, que se identifica con la noción burguesa pastoril tolstiana ${ }^{7}$ matan el tiempo, mientras aguardan que sus demás compañeros lleguen a ensayar. En un claro guiño al teatro chejoviano, los tres personajes esperan. Para ello, citan y actúan diversos fragmentos de escenas de las obras del autor, como El jardin de los cerezos, La gaviota e Ivanov; además, discuten sobre la situación político-social que acontece, por ese entonces, en el país. A petición de la propia Olga Knipper recrean las distintas versiones de la muerte de Chéjov. ${ }^{8}$

El montaje se articula, principalmente, en torno a la problematización de la acción, por medio del discurso verbal, en permanente tensión con el espacio interno y externo -el teatro y la revolución-, así como con su artificiosidad, es decir, con la representación en sí misma. Calderón pragmatiza cada secuencia de la obra desde una reflexividad escénica, en el ejercicio de revelar su propia construcción artificiosa al poner de manifiesto los compo-

7 A lo largo de toda la obra, Aleko pregona una visión de mundo cercana al georgismo -o georgism en inglés-, que fue respaldada por el escritor ruso León Tolstói hacia el final de su vida. De hecho, escribió el "Prefacio" para el libro de George, Social Problems, en donde ambos coincidieron tanto en el rechazo de la propiedad privada de la tierra, como también en la economía socialista de planificación centralizada. Muchos artistas e intelectuales de todo el mundo hicieron eco de esta "visión filosófica pastoril" de Tolstói, en que recomendaba austeridad en la comida y la bebida, la práctica de ejercicios de meditación, la lectura de salmos y pasajes bíblicos, el cultivo sustentable de la tierra y la vida retirada en el campo, entre otras cosas. Es más, en Chile se fundó la Colonia Tolstoyana, de la mano de Augusto d'halmar, Julio Ortíz de Zárate y Fernando Santiván, este último autor de Memorias de un tolstayano (1955). Su propósito era retirarse a un lugar apartado - ubicado en San Bernardo, en un terreno cedido por Manuel Magallanes Moure- para trabajar la tierra, leer, estudiar y crear en la tranquilidad espiritual y física que un estilo con dicha calidad de vida permitía. Por ello, las constantes alusiones de Aleko a la vida retirada y tranquila en el campo están en fuerte conexión con estos preceptos tolstianos; evidentemente, Calderón está al tanto de los mismos.

8 La anécdota de recrear una y otra vez la muerte de Chéjov podría ser leída intertextualmente con el cuento "Tres rosas amarillas", del escritor norteamericano Raymond Carver, en donde se ficcionalizan los últimos años de vida de Chéjov que antecedieron a su muerte por tuberculosis la madrugada del 2 de julio de 1904. Un momento central del relato tiene lugar durante la madrugada de una noche de verano, cuando Olga Knipper manda llamar al doctor Schwörer, preocupada por la salud de su esposo. El doctor, ante la inminente nula esperanza de la sobrevivencia del escritor, llama al personal del servicio del hotel para que le traigan una botella de champaña a la habitación. Una vez que Olga y el doctor destapan la botella, Chéjov perece. La historia de Carver finaliza con Olga Knipper en la soledad de la habitación de su hotel, haciéndose cargo de la muerte de su esposo. Guillermo Calderón, en Neva, intenta revivir una y otra vez este pasaje. 
nentes teatrales que la constituyen; o sea, al desplegar cómo una escena se constituye en sí misma como teatro. En consecuencia:

Si en la tradición teatral realista, la verosimilitud definía la relación que el espectador establecía con la obra, en Neva esta verosimilitud no es más que un anzuelo, una forma de seducir al espectador mostrándole una obra aparentemente tradicional, pero que sin embargo esconde una construcción (lenguaje, decorado, tiempo, espacio, etc.) que no hacen más que remitir a sí mismos, a su funcionamiento dentro de un universo autónomo y limitado. Este engaño pretende involucrar al destinatario, incomodándolo y suscitando en él una reflexión intelectual con respecto a la manera en que se produce la ficción dramática, ejercicio que le permite vincular indirectamente cómo ciertos discursos y prácticas constituyen los soportes de identidad en su realidad (Campos 7-8).

En Neva, entonces, se articula una serie de estrategias que plantean deconstruir la tradición realista previamente establecida a través de diversos mecanismos y estrategias escénicas, como son: su estructura metateatral, por medio de una propuesta de corte minimalista; un trabajo de dirección actoral, en donde se propulsa "lo real" sobre la verosimilitud realista tradicional, y una propuesta de trabajo de naturalización vocal por parte de los actores que permite canalizar la intensidad emocional.

\section{La metateatralidad como estética del despojo}

Para Soledad Lagos, el trabajo de Calderón opera centrado en una estética del despojo escénico, "donde lo único que cuenta son los actores y sus cuerpos puestos en espacio" (Neva: El río 17). A partir de una escenografía minimalista, compuesta solamente por una pequeña tarima en donde se sitúan los actores, una vieja silla de estilo clásico y una estufa, Calderón construye una atmósfera intimista y personal de un espacio privado minúsculo, concreto y singular: el de un ensayo teatral. La iluminación en penumbras, que cuenta principalmente con la luz que proviene de la estufa situada de cara a los actores -en la parte frontal baja de la tarima-, produce una atmósfera de candidez y cobijo que se contrapone al enfrentamiento verbal en el uso de la palabra durante todo el montaje, ya sea entre los enfrentamientos binarios de Olga-Masha, Aleko-Masha u Olga-Aleko. Estas constantes pugnas verbales entre los tres actores están intercaladas por las distintas improvisaciones y juegos de roles que realizan a lo largo del montaje, ya sea para recrear la muerte de Chéjov o para traer a escena la situación política que se vive afuera del teatro, puesto que: "La Historia 
que no es parte de la ficcionalización, la que está en las calles, irrumpe por referencias de Masha, quien, en forma muy lúcida, transmite lo que, para ella, terminará siendo eso que en ese momento ocurre afuera de la sala de teatro" (15).

En Neva es posible apreciar -como ya se ha remarcado anteriormente- una reflexividad en torno a su propia constitución como obra teatral, por medio del uso de recursividades metateatrales. Calderón plantea, en varias escenas, la posibilidad de distintos juegos de rol e improvisaciones, que se suceden unos a otros. Entre ellos destaca, primeramente, la escenificación de la muerte de Chéjov, en donde Olga hace un doble rol, pues no sólo es actriz, sino también directora de la muerte de su propio esposo; ella selecciona quién lo interpretará e indica cómo, supuestamente, fue el fallecimiento de éste:

AlEKO: Olga, yo interpreto a Antón.

OLGA: Gracias, Aleko.

MASHA: Yo también puedo interpretar a Chéjov.

OlgA: ¿Sí? (A Masha) A ver, tose. (A Aleko) Tose, Aleko (Aleko tose). Tose, Masha (Masha tose). (A Aleko) Tú vas a interpretar a Antón [...] Tú vas interpretar al doctor Schwörer. El doctor Schwörer tiene a Antón muy cerca y le está diciendo unas palabras en alemán que yo no alcanzo a escuchar. MASHA: Olga, yo no sé hablar alemán.

OLGA: (A Aleko) Ella es actriz y no sabe hablar alemán... ¿Entonces, cómo piensas? Vas a hablar alemán, porque el doctor Schwörer era alemán. En ese momento, tú le dices "ich sterbe".

AleKo: (A Masha) Me muero.

OLGA: En ese momento, Masha, le vas a inyectar alcanfor y luego [...] Te vas a tomar la copa, me la vas a pasar a mí... Y luego él va a morir... Va a morir, Masha. Gracias. Los dos son personas maravillosas. (Toman sus posiciones) ¡Acción! (Aleko tose).

MASHA: Soy el doctor Schwörer.

OLGA: ¡Doctor!

MASHA: Ich brait und wis if kurt nais kris yaikenshipnen... (Habla en alemán inventado. Aleko se ríe). Olga, yo no puedo seguir actuando, Aleko se está riendo de mi trabajo.

OLGA: ¿Cómo se te ocurre parar la escena cuando la escena acaba de empezar? [...] Y después me miras con cara de sorpresa cuando te digo que no tienes alma. ¿Te parece que es tener alma parar una escena en la mitad, cuando ya empezó? (Calderón 14-16). 
También son importantes las rencillas entre la hermana de Chéjov y Olga Knipper:

ALEKO: ¿Alguna escena en particular?

OlgA: Algo de mi vida. ¿Podrías actuar lo que le pasó a Masha Chejova, la hermana de Antón, cuando supo que nos íbamos a casar?

AleKo: (Como Chéjov) Masha, hermana, me voy a casar.

MASHa: (Como Masha Chejova) No.

ALEKO: Pero vas a vivir con nosotros.

MASHA: No. ¿Para qué te vas a casar, si yo te lo doy todo? [...] (A Olga) Cerda, alemana vil, te las arreglaste para atrapar a mi hermano. Si te conviertes en la Natasha de Las Tres Hermanas, te voy a estrangular con mis propias manos [...].

OLGA: Deja de hacer tantas clases, Masha. ¿Por qué no te enamoras? (25-26).

O las vicisitudes del pueblo ruso en aquel entonces, que parecen mezclarse involuntariamente con las del propio teatro: ${ }^{9}$

OlgA: (A Masha) Te da risa, te da risa que yo no sepa quién es Gapón. Pero, entonces, ríete, pero ríete más fuerte, ríete fuerte; si te vas a reír de mí, ríete fuerte. Que todo San Petersburgo se entere de lo cretina y estúpida que es Olga Knipper, que no sabe quién es Gapón. (Llorando) Yo no tengo por qué saber quién es Gapón, ¿por qué tengo que saber quién es Gapón? ¡Yo vengo llegando de Moscú!

ALEKO: Olga, siéntese, siéntese. Olga, el padre Gapón es el sacerdote que organizó la marcha de los trabajadores hoy en la mañana [...]. Olga, hoy en la mañana los trabajadores le llevaron una carta al zar [...]. La carta pedía justicia, protección. Decía: "Nos sentimos empobrecidos, oprimidos, nos tratan con desprecio, el despotismo nos está sofocando" [...].

OLGA. ¿Dónde está el padre Gapón? [...] ¿Murió?

$9 \quad$ Es interesante rescatar cómo, en Neva, es posible apreciar un gran trabajo de investigación historiográfica por parte de Calderón. La anécdota del escape disfrazado del sacerdote Georgy Gapon -que aquí se citano dista mucho de la realidad. Yedin Tova en -Maxim Gorky: A Political Biography-comenta que, tras el "Domingo Sangriento" del 22 de enero de 1905, Gapon efectivamente se escondió en la casa de Gorky, y fue el socialista Pinhas Rutenberg quien lo disfrazó de un "hombre común y corriente", para poder sacarlo de la ciudad. En un truculento giro argumental, Gapon murió asesinado poco más de un año después, en su retorno a San Petersburgo, al ser traicionado por el propio Rutenberg ante la Policía Secreta. 
MASHA. No, Olga. No está muerto.

OLGA. ¿Y tú cómo sabes eso?

MASHA: Yo estuve con el padre Gapón antes de llegar a ensayo. En la casa de Gorki.

OLGA: ¿Tú estuviste en la casa de mi amigo Máximo Gorki?

MASHA: Gorki me llamó. Necesitaban una actriz que supiera de maquillaje. Tenían que sacar al padre Gapón de la ciudad. Yo lo pinté de mujer y le puse una peluca (32-34).

La propuesta directorial de la obra descansa, así, en llevar a escena el nivel discursivo a través de una estructura metateatral. Aunque, en repetidas ocasiones, la prensa y la crítica ${ }^{10}$ han llamado a Calderón como "autor de texto", su trabajo dista mucho del entendimiento de un teatro meramente de discurso. Para Tobin Nellhaus: "Los discursos, lejos de ser solamente lingüística, se construyen con los iconos, índices y símbolos; y son elaborados en forma de articulaciones analógicas, expresivas, y lógicas. Aunque sus agentes entiendan sus acciones y las circunstancias que los rodean, y que orientan o motivan sus acciones posteriores" (151). ${ }^{11} \mathrm{Si}$ bien, las prácticas discursivas primariamente envuelven significados, ideas, imágenes y valores, también encarnan interacciones sociológicas materiales. Los discursos en Neva implican interacciones entre individuos o grupos, por lo que, consecuentemente, requieren de una audiencia o de un otro que pueda descifrar las actividades físicas involucradas en ellos, como son la producción de sonidos, las marcas gestuales o las muletillas (ibídem). La propuesta metateatral que la obra plantea se configura, bajo esta lógica, no como una apuesta estética o una estrategia dramatúrgica, sino como una decisión de dirección que descansa en la preocupación de dotar de sentido y significado a la palabra desde su condición material; es decir, desde la acción de comunicar, dado que: "La comunicación es una práctica productiva. Puesto que la comunicación produce varios efectos, incluyendo los significados y las relaciones interpersonales o sociales, se pueden lograr cosas mediante la comunicación [...] todos los actos de habla y, la comunicación en general, son performativos" (ibídem). ${ }^{12}$

10 Carola Oyarzún remarca esta condición que le ha dado la crítica a Calderón, pero agrega que su fuente de trabajo es múltiple, por ende este "mote" que ha recibido por parte de la crítica de prensa especializada no es el único o el gran elemento definitorio de su poética (303-305).

11 [Cita original]: "Discourses, far from being solely linguistic, are built with icons, indexes, and symbols, elaborated in the form of analogical, expressive, and logical articulations. Though them agents understand their actions and the surrounding circumstances, and which guide or motivate their subsequent actions".

12 [Cita original]: "Communication is a productive practice. Since communication produces various effects, 
En Neva, el mecanismo principal, develado a lo largo del montaje, es el teatro en sí mismo. Los actores, una y otra vez, ejecutan juegos de representación en distintos niveles, ya que, al final de cuentas, la obra pone en el escenario a actores que actúan de actores y que, a su vez, están actuando y "dejando de actuar" repetidamente. La elección de instalar la metateatralidad como estrategia predominante en esta puesta en escena no es más que la apuesta directorial por tratar de develar la propia esencia del teatro en sí mismo: "El Metateatro, sobre el que podría estar tentado a concluir, que es la esencia pura del teatro; el teatro relevado de todas las demás obligaciones, excepto de la celebración de sí mismo" (12). ${ }^{13}$ Surge, entonces, la necesidad de reparar en qué lleva a Calderón a instalar la pregunta por la propia condición material del teatro en esta primera obra; es decir, por qué y cómo la metateatralidad puede constituirse a sí misma como una metodología de trabajo escénico. Tobin Nellhaus propone, a este respecto, que la metateatralidad puede ser entendida como una metodología para el trabajo de creación escénica, ya que, por una parte, produce una creación, mientras que también, por otra, dota y provee de significado: "La preocupación de la producción [de las obras metateatrales] generan algo nuevo, una variedad de significados, emociones y sensaciones en una audiencia; se refieren a los efectos que no se puede considerar en el acto de habla y en la performance porque no se realizan a menos que logren algún efecto sobre esa audiencia" (151). ${ }^{14}$

La metateatralidad, entendida como una estrategia de dirección, demanda de una reflexividad que deja al descubierto la ilusión y la artificialidad del teatro en sí mismo, por medio del ejercicio actoral. Para Mary Ann Frese Witt, toda pieza metateatral se sitúa en una mise en abyme, en una situación de espejo que demanda autenticidad por parte de sus participantes; en este caso, de los actores: "La cuestión de la autenticidad se convierte en lo primordial. Jugando un papel en el metateatro, un actor puede ser más auténtico que los que están fuera del teatro jugando hipócritamente papeles en lo que pasa en la realidad" (171171). ${ }^{15}$ Esta sería, precisamente, la operación directorial que Calderón propone en Neva;

including meanings and interpersonal or social relations, one can accomplish things by communicating [...] every speech act, and communication in general, is performative".

13 [Cita original]: "Metatheatre, we might be tempted to conclude, is the pure essence of the theatre, the theatre relieved from all other obligations except from celebrating itself".

14 [Cita original]: "The concern [the metatheatrical's plays] production because they generate something new, an array of meanings, emotions and sensations in an audience; they concern effects because no speech act and no performance can be considered performed unless it achieves some effect upon that audience".

15 [Cita original]: "The question of authenticity becomes primary. Playing a role in the metatheatre, an actor may be more authentic that those outside the theater hypocritically playing roles in what passes for reality". 
su propia metodología es revelada en una mise en abyme de sí misma. Por tanto, el propio montaje se convierte en memoria y encarnación del trabajo metodológico realizado durante los ensayos. En este caso, sería utilizar la metateatralidad para escenificar cómo el personaje quiebra la artificialidad de la representación, para insertarse como actor -o actor/personaje como propone Nellhaus- y, así, trasladar la escena desde "lo real" hacia el artificio: "Cuando los personajes en el escenario eliminan el aparato creacional ilusorio para revelarse a sí mismos como actores, y al escenario como un lugar de representación de un palacio o una sala de estar, se mueven, paradójicamente, de lo irreal a lo real a lo irreal" (172). ${ }^{16}$

La gran paradoja de la metateatralidad consiste en que más real -o verosímil- se plantea la obra cuanto más abiertamente abraza el artificio. Como bien ocurre en Neva, cuando Aleko le declara su amor a Olga, pero en realidad estaba actuando; Olga se muestra desolada, y cuando Aleko trata de consolarla, ésta también revela que se encontraba actuando:

ALEKO: Olga, le quiero pedir perdón.

OLGA: ¿Por qué, Aleko?

ALEKO: Porque me enamoré de usted cuando la vi actuar Las Tres Hermanas hace un par de meses en Moscú. Me enamoré tanto, Olga, que me orino en la cama.

OLGA: Aleko, yo ya amé, yo ya quemé mi carbón y mi aceite.

ALEKO: Entonces sálveme, Olga, perdóneme. Yo le deseaba la muerte a su Antón y mi deseo se cumplió. Olga, por favor, perdóneme; soy una persona tan simple. Por favor, perdóneme, Olga.

MASHA: Permiso, voy a buscar hielo.

ALEKO: ¡No, no te vayas! ¡No me dejes solo con ella! Olga, soy una costra [...]. El órgano más importante de mi cuerpo es mi apéndice y quiero metérselo en su riñón y verla sudar.

MASHA: ¡Aleko!

OLGA: Siga, siga [...].

ALEKO: No, ya terminé.

OlgA: Sucio, boquita de postre. No me puedo mover.

ALEKO: Es un monólogo que estoy ensayando basado en Dostoievski. ¿Le gustó? $[\ldots]$.

OlgA: ¿No me ama? (Olga llora).

16 [Cita original]: "When the characters on stage remove the illusion-making apparatus to reveal themselves as actors and the stage as a stage rather than a representation of a palace or a living room, they are, paradoxically, moving from the unreal to the real to the unreal". 
ALEKO: No. (Consolándola) Olga, Olga, cualquiera se enamoraría de usted. OLGA: ¿Estaba actuando?

ALEKO: Sí.

OLGA: No actúe nunca más, por favor (Olga pasa bruscamente del llanto a la risa).

MASHA: (Sorprendida) Olga, usted es muy buena actriz.

OLGA: No. Era (19-20).

Pareciera que en este juego metateatral, en que los actores actúan para dejar de actuar y volver a actuar después, radicaría no sólo la paradoja propuesta por Mary Ann Frese Witt, sino que también la esencia misma del acto teatral, ya que:

El contacto entre los cuerpos vivos en el escenario y una audiencia en vivo -o incluso imaginando la performance en la lectura "literal" de teatro- todavía tiene el potencial para ofrecer una experiencia transformadora que los medios más sofisticados técnicamente no lo hacen. Teatro que se refleja sobre sí mismo como el teatro que seguirá manteniendo el poder de la magia teatral (173-174). ${ }^{17}$

Es en este sentido la propuesta directorial de Calderón, en Neva, no hace más que entender la propia exégesis del teatro al querer revelar $-\mathrm{y}$ al conseguirlo exitosamente- en escena la propia naturaleza del teatro, porque como bien considera Martin Puchner: "Si entendemos el metateatro como el momento cuando el teatro viene hacia sí mismo, ya no es sorprendente, sino que es casi imposible para el teatro no convertirse en metateatro. Porque, ¿cómo podría cualquier teatro, no sé, de alguna manera, y demostrar que sabe, de alguna manera, lo que significa ser teatro?” (13). ${ }^{18}$ En consecuencia, para lograr este cometido, es que Calderón apela a un "ultra-naturalismo" -en términos de Nellhaus-, para poder escenificar la meta-reflexividad que Neva propone como pieza escénica: "Esta implosión teatral hacia lo que realmente está presente en el momento de la actuación podría, estéticamente hablando, ser nombrada como un estilo de ultra-naturalismo" (176). ${ }^{19}$ Bajo la considera-

17 [Cita original]: "The question of authenticity becomes primary. Playing a role in the metatheatre, an actor may be more authentic that those outside the theater hypocritically playing roles in what passes for reality".

18 [Cita original]: "If we understand metatheatre as the moment when theatre comes to itself, it is no longer surprising that it is almost impossible for the theatre not to become metatheatre. For how could any theatre not know, somehow, and show that it knows, somehow, what it means to be theatre?".

19 [Cita original]: "This theatrical implosion into what is actually present at the moment of performance might, aesthetically speaking, be called a style of ultra-naturalism”. 
ción de una puesta en escena fascinante y sugestiva, la metodología directorial descansa en considerar a los actores como agentes del verbo y de una self-presence -o reflexividad de la presencia en sí misma- para instalarnos en un nivel ontológico de sentido.

Conforme a esto, la performance de la performance da cuenta de un nivel metadiscursivo ulterior que, en este caso, corresponde al mensaje final de la obra, encriptado en el monólogo final de Masha, interpretado por Paula Zúñiga. La estructura teatral que componen los actores/agentes durante toda la obra es una preparación para este momento, en donde la obra da un salto o giro ontológico, en el que los agentes virtuales -personaje Masha- se desplazan hacia agentes reales -actriz Paula Zúñiga interpelando al público presencialmente real-. Y es, justamente, en este salto/giro/desplazamiento en donde es posible vislumbrar el quiebre con el artificio que había sido abrazado previamente durante todo el montaje; he ahí aquel punto en donde "lo real" hace mella la escena, para irrumpir con profunda fuerza a través del trabajo de dirección actoral.

\section{"Lo real" como improvisación para una metodología actoral}

En Neva, Calderón ejecuta un cuestionamiento sobre la naturaleza de la acción teatral, en cuanto a su condición de verdad y artificialidad. A lo largo de la obra, los actores cuestionan los métodos de actuación proscritos para su época, dadas las condiciones interpretativas, supuestamente extraordinarias, de Olga Knipper; el talento para la improvisación lúdica por parte de Aleko, y las limitadas -en teoría- dotes actorales de Masha.

El proceso de ensayo -según afirma el propio Guillermo- parece no tener una lógica preestablecida, aunque a la luz de los años y tras varios montajes a su haber, es posible refutar esta primera impresión del teatrista chileno:

Metodología no hay, pero sí una forma que se repite, aunque no alcanza a definirse [...] Una vez que está la idea y los actores van a actuar, comienza la etapa de escribirla. Voy escena a escena. Por lo general cuando al final, al principio y lo que sucede en el medio. Escribo las escenas, y en los ensayos me interesa ver cómo los actores van reaccionando al texto, voy escribiendo a partir de eso. Por ejemplo, pueden haber cosas que a ellos no les resuenan mucho, es decir, está muy vinculado a quienes lo van a interpretar. Hay mucha edición de puesta en escena, y es que me voy adaptando a ellos, como dije antes, a sus reacciones (citado en Baboun 22-23).

En cada ensayo, Calderón busca establecer un mapa de la memoria de los cuerpos en escena; es decir, como director registra las pequeñas reacciones que los actores van 
teniendo en cada ensayo y, a partir de ellas, continúa construyendo las escenas del montaje. Aunque la estructura total ya haya sido trazada en su globalidad, los ajustes y el devenir de la pieza en sí van siendo creados en su trabajo de dirección en los ensayos en conjunto con los actores.

Para Isabel Baubon, el trabajo de ensayo de Calderón "parece convertirse en una actividad de prueba donde la materia prima o primera sustancia corresponden al actor, como un sí mismo indisoluble entre texto y escena. Es el actor quien instala preguntas, conflictos y oposiciones entre el primer paso o traspaso de la escritura, siendo el carácter y reacción del propio intérprete esencial para nuevas texturas y decisiones de estilo" (ibídem 23). El texto, por ende, adquiere una densidad mnemotécnica, gracias a la capacidad de recordarse a sí mismo a través del trabajo de improvisación actoral realizado en cada ensayo: "Podemos incluso identificar sin realizar un difícil rastreo, palabras y formas del decir en los personajes, acusando un metalenguaje que posibilita todavía más la relación de ellas entre sí" (23).

"Lo real" aparece en su propia condición metodológica en cuanto metalenguaje escénico que busca poner en crisis su propio contexto de producción; vale decir, a la obra de arte en sí misma o, en este caso, al propio teatro. A este respecto, para Adorno: "En virtud de la contradicción entre este objeto conciliado en la imagen (es decir, espontáneamente acogido por el sujeto) y la exterioridad objetiva inconciliada, la obra de arte critica la realidad. En esto consiste su conocimiento negativo de la realidad" (52). En el caso de Neva, el objeto conciliado en la imagen -a la que alude Adorno- no sería otro que el cuerpo de los actores. Éstos, por medio de su actuación, mediada por el trabajo de dirección de Calderón, consiguen aquella exterioridad objetiva inconciliada; en el ejercicio de hablar y de hacer teatro en el acto de reflexionar sobre el mismo, como bien ocurre en la serie de juegos representacionales que suceden a lo largo de la obra. Es así que "lo real" irrumpe en escena: "Sólo en virtud de esta diversificación y no en virtud de su negación, la obra de arte se hace a la vez obra de arte y justa conciencia. Una teoría del arte que lo ignore es simultáneamente vulgar e ideológica" (52).

La metodología directorial que Calderón persigue -conscientemente o no- en Neva descansa en el ejercicio de referenciar el propio teatro a partir del trabajo de improvisación actoral que vaya sucediendo en los ensayos. En este sentido, la metodología se transforma en el propio metalenguaje que todo el tiempo está en un diálogo intrínseco con el self de la obra. Como el propio director declara:

En el teatro contemporáneo es casi inevitable metalenguajear, hacer referencia al propio lenguaje de una forma autorreferente, irónica. No puedo plantearme tan ingenuamente frente al medio en el que estoy inmerso, tengo que referirme a él. Y hacerlo 
no es pensarlo como vanidoso, sino más bien como una reflexión necesaria al propio trabajo. Ponerlo en crisis, enfrentarlo al escenario, cuestionarlo como un elemento dentro de una totalidad y no como algo fundamental, que muchas veces ocurre donde la obra entera está definida por una relación conflictiva del lenguaje escénico, lo que puede ser interesante, pero que a mí no me parece tanto como para definir así una obra entera (citado en Baboun 23).

La capacidad de realizar esta labor se ve facilitada por el conocimiento previo que Guillermo Calderón tiene para con los intérpretes, en particular con las actrices Trinidad González y Paula Zúñiga, con quienes no sólo había trabajado previamente, sino con quienes también creó la Compañía El Cancerbero. Después de un par de años, Calderón y González viajaron a Estados Unidos para seguir perfeccionándose, situación que también hizo Zúñiga, por su parte, quien viajó a India e Italia. Una vez que ambas actrices regresaron a Chile, quisieron trabajar juntas nuevamente, pero se les había unido el actor Jorge Becker. En un comienzo, la primera motivación de Guillermo Calderón fue llevar a escena Las muertes de Chejov, ya que venía hace ya varios años fanatizando con la literatura rusa, y llegó a la primera reunión con los actores solamente con el monólogo inicial de Olga Knipper con el que comienza, de hecho, la obra.

Las demás escenas surgieron -tal como él declaró en la entrevista realizada por Baubouna partir del proceso ligado a los ensayos. Calderón tenía clara una idea, en donde había tres actores que hablaban y hacían teatro, pero aquello de lo que hablarían y cómo lo personificarían surgió en un proceso basado en el trabajo de improvisaciones realizado con los actores a partir de una escaleta estructural de la obra que ya existía desde un comienzo, pero que se fue construyendo en su totalidad -salvo el final que Calderón tenía claro desde un principio-durante el proceso de montaje (Corbalán 1-6). A raíz de esto, podría pensarse que, al ser un texto escénico que surge en gran parte a partir de los procesos de ensayo, hubo creación colectiva coral con los actores. Pero, más bien, el fenómeno transitivo que aquí ocurrió fue de un proceso de "inspiración" o feedback dramatúrgico que se dio tras los ensayos, por el desempeño de los actores, quienes iluminaron el trabajo escritural de Calderón. Por tanto, el director no escribió para cualquier actor, sino que lo hizo directamente enfocado con los tres intérpretes con los que trabajó: González, Zúñiga y Becker.

"Lo real" aflora, bajo este prisma, como la presencia de lo relacional mediado por el proceso de improvisación y réplica que los actores propusieron en cada ensayo, puesto que lo real es, en sí, relacional. El teatro, dentro del teatro, como estado de encuentro: "La esencia de la práctica artística radicaría entonces en la invención de relaciones entre sujetos; cada obra de arte encarnaría la proposición de habitar un mundo en común, y el trabajo de cada artista, un haz de relaciones con el mundo que a su vez generaría otras relaciones, y así hasta 
el infinito" (15). Calderón restableció, en su trabajo con los actores, un espacio de encuentro en el proceso de creación artística e invitó al espectador a sumarse al mismo. Puesto que, como él afirma -en diálogo con Soledad Lagos-, éste debió ser un ente activo en el proceso interpretativo de la obra: "Hay gente que se frustra un poco, porque piensa que necesita más tiempo para digerir cada idea, pero la idea era que fuera un flujo, que fuera más una impresión general que caer en la tentación de lanzarle al público textos predigeridos" (Tres actores 8). Es el espectador quien debía decidir desde dónde emergía la obra para él, pues Neva se compuso como un devenir discursivo de ideas bajo la premisa de conseguir "que fuese una angustia apabullante y que dejara en crisis al espectador, sin que él supiera si abordar eso de modo intelectual o emocional, para que quedara una especie de neblina" (8).

En Neva, Calderón realizó un trabajo de puesta en escena, en donde documentó el propio proceso de los ensayos. Como bien rescatan Paula Zúñiga y Trinidad González, la obra visualiza de manera patente los propios hallazgos que el grupo descubrió y trabajó durante los ensayos. Bajo esta consideración, la obra se pliega a los procesos artísticos de hacia finales de los años 90 y principios del siglo xxi que, como indica José A. Sánchez, no buscan romper definitivamente con lo espectacular o lo objetual, como ocurría en la década de los 60, por ejemplo, sino que intenta proponer lo espectacular y lo objetual como generadores de la acción: "es el objeto [...] el que provoca la acción de aquel o aquellos con quienes entra en relación a quienes anima una relación y una organización formal, y es finalmente esa organización formal la que cumple el objetivo de la obra artística" (278). Por tanto, este devenir de ideas se encarna en los actores para producir una organización formal generadora de un momento de sociabilidad con su audiencia, siendo ella la última encargada de decidir cómo abordar el objeto artístico; en este caso, la significancia ulterior del montaje en sí. Cabe rescatar, empero, que también existe una posibilidad inversa: "la consideración del objeto o del espectáculo en cuanto documento de un proceso de relaciones previas, sin que de ello se deduzca la total desvalorización de lo que se muestra al final, y que se contempla más bien como límite, y no como huella, pero tampoco como resultado o producto" (278). Calderón da cuenta de esta otra consideración en su entrevista con Soledad Lagos, al constatar las diversas apreciaciones que la variedad de público puede proscribir para con Neva: quedarse con la historia de una viuda que llora a su marido, de actores que actúan de actores, o con el conflicto político-ideológico que reflexiona sobre la violencia y la revolución social del pueblo.

Aunque podría decirse que operan, al unísono, una simultaneidad de significancias y consideraciones con las que los espectadores podrían quedarse tras ver el montaje, Calderón realiza un último gesto de dirección que termina por entregar una pista clave al público a la hora de otorgarle un sentido global a la pieza: el gesto de la estufa. Una vez terminado el apabullante monólogo de Masha -en donde ésta increpa a Olga y Aleko por su aparente escaso entendimiento de que está a punto de escribirse una revolución popular sangrienta 
y de que el teatro no sirve de nada para cambiar la Historia-, se produce un instante de silencio pequeño. Zúñiga ha acabado de interpretar un monólogo extenso que en apariencia no ha terminado, pues lo ha interrumpido al "dejarse caer" a un costado de la pequeña tarima, desapareciendo de escenario; en ese momento, Bécquer gira la pequeña estufa -que ha estado iluminando a los actores durante toda la obra- hacia el público, encandeciéndolos brevemente, antes de ejecutar el apagón final. Este último gesto teatral cobra suma importancia, pues el acto de "cegar" al espectador -aunque sea momentáneamente- se consigna como la última acción performática del montaje.

La realización de este gesto final brinda al espectador una clara pista con respecto al propósito ideológico que el monólogo de Masha ha suscitado y se consigna como una clara acción que busca incluir al público en la propia discusión que la obra ha planteado. Este gesto es de suma importancia no sólo para el fin de análisis del Neva, sino que es clave para toda la obra de Calderón, puesto que -como se verá a continuación en este y el próximo apartado- las obras de Guillermo muestran un patrón común: el de finalizar con un gesto escénico rotundo, con una acción particular y específica, desprovista de texto. Después del viaje emocional y de la lluvia de ideas, que Calderón ha propuesto durante todo el montaje, la decisión de cerrar con este gesto escénico profundo y tajante, puede ser traducida como una decisión de dirección, en que se busca cerrar la cadena significante de la obra dotándola del sentido ideológico que se ha estado persiguiendo a lo largo de todo el montaje. Es así que el gesto metateatral final se transforma "en Neva" en el epítome de la reflexividad escénica que el teatro de Guillermo Calderón trabajará en sus siguientes montajes.

\section{Más allá del sentimiento: la emoción y el uso de la voz}

En Neva, Calderón instala -como ya se ha mencionado anteriormente- un teatro de las ideas, en donde plasma sus reflexiones ideológicas y políticas sobre el teatro, el amor y la revolución social. ${ }^{20}$ Este ejercicio se instala desde una práctica prominentemente metateatral, en la que fue clave el trabajo de improvisación con los actores durante el proceso de ensayo. Pero también parece importante rescatar que este "teatro de ideas" no debe ser entendido solamente como un ejercicio de reflexividad, sino como un flujo

20 En la entrevista "Neva: Tres actores en escena, una estufa, algunas sillas. Diálogo entre Guillermo Calderón y Soledad Lagos a propósito de Neva", realizada por Soledad Lagos, Calderón comenta que en el caso de esta obra persiguió dar cuenta de dos ideas políticas que confluían dentro de él y que se plasman en los personajes de Masha y de Aleko. Estas serían: la revolución social anarquista, destinada a la muerte de sus partidarios en los gulag, y el sueño retrospectivo tolstiano de segregarse al campo para abrazar la vida pastoril. 
emocional que encarnan los actores en escena. Un claro ejemplo de que este tránsito desde las ideas hacia las emociones ocurre hacia el final de la obra es el monólogo de Masha. Para Calderón, este tránsito es de suma importancia y da cuenta de una intención clara que persigue a lo largo de toda su obra; frente a este trabajo -en conjunto con la actriz Paula Zúñiga- declara:

Cuando ella tomó el monólogo, quería hacer lo que se hace de manera convencional, que es poner una idea detrás de cada texto, de tal modo que el texto quedara comprendido y explicado, pero mi indicación fue que fuera una especie de... que se subiera a un carro, digamos y se fuera con ese carro, que hubiera un flujo emocional más que un flujo intelectual. Mi idea era que, como espectador, uno se cuelgue de una emoción y que escuche esta idea intelectual, pero que no sepa con exactitud por cuál camino irse: si quedarse con lo intelectual o lo emocional, y que se produzca una experiencia un poco apabullante, que vaya más allá de lo racional (citada en Corbalán 7).

Surge, entonces, la pregunta de cómo trabajar este flujo emocional con la actriz y desde la actriz hacia el público presente. Es, en este momento, que el uso de la voz se convierte en un vehículo para ello.

Bunch Dayme considera que el trabajo con las emociones en teatro es sumamente difícil, pero de vital importancia: "Las emociones pueden curar, o crear el caos con el campo de energía [...]. La emoción es un tema que por lo general se ignora o se omite, ya que es difícil de cuantificar" (6-7). ${ }^{21}$ Frente a este problema de cuantificación emocional, Bunch concluye que el ejecutante debe trabajar con un observador externo que lo ayude a encontrar una emoción pura con la cual el espectador pueda empatizar:

Para que el intérprete pueda escuchar de esta manera, se exige un desprendimiento completo; casi la de un estado mediador o la de una tercera persona que ve desde el exterior. Como el "observador", el intérprete también puede entonces permitir que el sonido usado para contar su propia historia sin interferencias, esto debido a que la producción simultánea y la percepción de la misma forma emocional no pueden ser llevadas a cabo por el sistema nervioso y sin un grado de interferencia. Las formas puras emocionales inducen la empatía y se experimentan como "sinceridad" por el público (7). ${ }^{22}$

21 [Cita original]: "Emotions can heal, or create chaos with the energy field [...] Emotion is a topic that usually is ignored or omitted because it is difficult to quantify".

22 [Cita original]: "For the performer to be able to listen in this way, demands complete detachment; almost that of a mediative state or that of a third person viewing from the outside. As the 'observer', the perform- 
Desde la perspectiva de Bunch, la emoción aflora gracias a un trabajo vocal que busca instalar un uso natural de la voz. En este sentido, una vez que el actor "suena natural", puede liberarse a sí mismo y dejar correr la emoción, para que: "Entonces toda esa energía fluirá en una palabra, una frase y una necesidad de llegar al mundo, simplemente a través de una combinación de sonido y el lenguaje" (Rodenburg 26). ${ }^{23}$ Esta "voz natural" no debe ser entendida como una voz "no teatral", sino más bien como un recurso teatral en donde la voz se trabaja desde la propia naturalidad y singularidad de cada intérprete, sin intentar forzarla, engolarla o disfrazarla hacia otra voz (26-28). Es desde este mismo entendimiento sobre los tratamientos del trabajo vocal que Guillermo Calderón realiza su trabajo de dirección actoral en Neva: contraponiendo una propuesta de naturalización del uso de la voz en los personajes de Masha, Olga y Alejo con otra propuesta del uso de la voz un poco más engolada y teatral una vez que estos interpretan otros personajes.

Para lograr este cometido, el trabajo vocal debe ser preciso en su repetición para que se pueda transmitir con claridad la idea a comunicar. A este respecto, Calderón ha declarado que las ideas son cruciales en su teatro. Por tanto, la manera en que éstas son transmitidas es sumamente importante, tal como argumenta Clynes:

Performear/actuar de forma natural significa dos cosas: [1] escuchar interiormente con la máxima precisión a la forma interna de cada sonido musical; y [2] producir esa forma precisa. Lo cual significa tener una idea precisa, así como una ejecución precisa de la misma. Y el hecho crucial y sorprendente es que si uno realmente cree esto y escucha con gran cuidado, entonces también resulta ser algo hermoso (12). ${ }^{24}$

La emoción se vuelve la base axiomática desde la que los actores construyen sus personajes en Neva, guiados por la dirección de Guillermo Calderón. En este sentido, puede afirmarse que, en este montaje: "Resulta que la memoria es en realidad una proteína"

er can then allow the sound to tell its own story without interference because simultaneous production and perception of the same emotional form cannot be carried out by the nervous system without a degree of interference. The pure emotional forms induces empathy and is experienced as 'sincerity' by the audience".

23 [Cita original]: "Then all that energy will flow into a word, a sentence and a need to reach out to the world, purely through a combination of sound and language".

24 [Cita original]: "Performing naturally means two things: [1] to listen inwardly with utmost precision to the inner form of every musical sound, and [2] the to produce that form precisely. It means to have a precise idea, as well as a precise execution of it. And the crucial and amazing fact is that if one really believes this and listens with great care, then it also turns out to be beautiful". 
(Bogart xviii), ${ }^{25}$ en sintonía con entender que la verdadera raison d'être del teatro no es otra que proveer de sentimientos al público. En el caso del teatro calderoniano, se propone la construcción de una emocionalidad con sentido, ideológica y afectivamente erguida desde un lugar político o, como él mismo lo ha definido, un teatro de las ideas.

La producción del trabajo emocional en Neva no es -en lo absoluto- una labor sencilla. En palabras de Erin Hurley: "Si la emoción se construye en la relación entre la escena y la audiencia (el estímulo y el receptor, si se quiere), no puede ser simplemente proyectada por los actores y capturada como la misma emoción, por parte del público. El trabajo emocional del teatro, es, en parte, una negociación" (20). ${ }^{26}$ Durante toda la obra existe un constante juego metateatral, en el que los personajes saltan de un personaje a otro; por ejemplo, Aleko interpreta a Chéjov, o Masha es la hermana de éste, siendo dicho juego revelado frente a los espectadores. Este juego es -en la terminología de Hurley- la negociación que Calderón pacta desde la dirección de actores hacia la audiencia, un juego que es ejecutado desde un trabajo emocional mediado por el uso de una voz natural. En Neva -y en el resto de sus obras-Calderón apela por una apuesta de naturalización del registro vocal, en la que el uso de la voz trata de asemejarse lo más posible a la voz natural que cada uno de los intérpretes -González, Zúñiga y Becquer- poseen en su vida cotidiana.

La claridad en el uso de la voz - como una instrucción de dirección que puede ser vista en toda la obra del autor- repercute no sólo en un acercamiento a lo real dentro de la construcción escénica, sino que también hay en ella una puesta en valor de la emoción que cada uno de los actores siente y reproduce función a función. Esto no es sólo trabajado desde la dirección y la puesta en escena, también desde el tratamiento dramatúrgico por parte de Calderón. La claridad del lenguaje en el texto dramático busca ser plasmada, asimismo, en la escena, ya que: "La claridad del lenguaje es crucial, pues es un reflejo directo de la claridad en la relación con la imagen y la acción. Si el lenguaje cambia o no está claro, la imagen cambiará o no será clara; y esto se manifiesta en el cambio de falta de claridad en la acción, que es una consecuencia y respuesta a la imaginación" (Boston 134). ${ }^{27}$ Es así que la claridad del lenguaje -tanto en el texto dramático como en la ejecución performática del mismoprovee al actor de una situación desde donde trabajar la emoción por medio de la acción y

25 [Cita original]: "It turns out that memory is actually a protein that is formed in the heat of experience".

26 [Cita original]: "If emotion is made in the relationship between stage and audience (the stimulus and receiver, if you will), it cannot simply be projected by actors and caught as the same emotion by the audience. The theater's emotional labour, the, is, in part, a negociation".

27 [Cita original]: "Clarity of language is crucial, for it is a direct reflection of clarity in relationship to image and action. If the language changes or is unclear, then the image changes or is unclear; and this manifests itself in changor lack of clarity in the action, which is an outgrowth of and response to the imagination". 
la naturalización vocal, para reflejar una imagen que podría ser entendida como la "idea de base" ${ }^{28}$ desde la que Calderón articula todos sus trabajos.

Por medio del uso vocal de un registro natural, Calderón busca liberar la voz para producir en el espectador una comunicación expresiva instalada, al mismo tiempo, en un plano emocional, y en otro, racional. Esta situación es llevada a su nivel máximo de ejecución durante el monólogo final de Masha, que indica que: "[el uso de] La voz natural libre es transparente: expresa, mas no describe, nuestros impulsos sentipensantes (de sentimientos y pensamiento) en forma directa y espontánea. De esta manera, escuchamos a la persona, no simplemente su voz" (Ocampo 18). Así, Calderón da los primeros pasos en busca de una recursividad sonora natural a través del registro vocal de sus actores en escena, recurso que seguirá trabajando en sus siguientes piezas y que radicalizará como técnica, a medida que avanza su carrera como director.

\section{Breve reflexiones de cierre (o la revalorización tradición teatral)}

A partir de una escena que juega desde el despojo escénico, consignado en el minimalismo escenográfico y lumínico, Calderón propone una dramaturgia de la palabra, ${ }^{29}$ del sonido en que "el poder expresivo se basa en la interminable relación conflictiva entre visualidad y auralidad reflejada en el choque entre la forma de las letras y el sonido de los fonemas, entre el texto escrito/impreso y la pronunciación vocal" (Ovadija 19). ${ }^{30}$ A través de una profunda preocupación por la palabra, articula una propuesta que se centra en el trabajo de dirección con los actores, sin forzarlos a emocionarse ni a ser grandilocuentes, casi en un

28 Por "idea base" me refiero a la situación común en el trabajo de Calderón, quien a partir de una idea primaria construye todo su universo teatral. En la entrevista "Neva: Tres actores en escena, una estufa, algunas sillas. Diálogo entre Guillermo Calderón y Soledad Lagos a propósito de Neva”, Calderón cuenta que su modo de trabajo nace a partir de una idea que él busca trabajar íntegramente al situarla en contexto con sus actores.

29 Es concordante que Juan Andrés Piña destaque que: "En este contexto, no es extraño que Calderón haya sido saludado como un [autor] de la renovación, por trabajar sobre la base de una poderosa verbalidad, para estructurar con ella un universo reflexivo y atento a los acontecimientos del mundo y de Chile, y capaz de formular interrogantes a las verdades recibidas. Todas sus obras se sostienen en largos parlamentos que los personajes se dicen a sí mismos o a los demás, creando con ello una singular poética que va desde la apagada sordina interior hasta alcanzar niveles épico” (168-169).

30 [Cita original]: "expressive power builds on the endless conflicting relationship between visuality and aurality reflected in the clash between the shape of letters and the sound of phonemes, between written/ printed text and vocal utterance". 
acto performático de resistencia a la teatralidad, en pos de organizar el sonido de la palabra dicha como única protagonista. Por tanto, "al concebir un método de composición o construcción teatral que diga su propia 'trama' a través del proceso de una semiosis oral/aural, la dramaturgia del sonido se ha convertido en constitutiva de un teatro que pone más énfasis en la performance, la puesta en escena y la arquitectura audio-visual del escenario, que en relación al texto dramático" (19). ${ }^{31}$

Podría enunciarse que -a final de cuentas - el trabajo de dirección que Calderón ha establecido - desde sus inicios hasta la fecha- instala una cartografía de la palabra escénica a partir de un cuidado tratamiento de la voz natural con los actores, cada vez más radicalizado en sus montajes -llegando al uso de microfonía en sus últimos trabajos para no 'forzar' la voz de los intérpretes-. Acompañándose -en el caso concreto de Neva-, de un minimalismo escénico y de una serie de recursos metadramáticos que persiguen revalorizar un modelo teatral fundador del teatro moderno chileno: "el del realismo sustentado en la complicidad estética entre Antón Chéjov y Stanislawski” (Hurtado, Prólogo 44).

Pues bien, estos recursos metateatrales no son más que, en esta lógica, una recursividad política, en la cual Calderón se instala desde una posición autorreferencial como agente (Nellhaus), pero no sólo para hablar de sí mismo, sino también para instalar un proceder dialógico crítico con respecto a aquello que le rodea; vale decir, estando siempre lo metateatral al servicio de un proyecto mayor, como la crisis de la memoria, lo íntimo y lo político, todas ellas trampas y equívocos que el imperativo de esta tradición metodológica-realista deja -según Calderón- en sus intérpretes. Para el autor, los espacios personales de sus actores son emplazamientos políticos que problematizan los métodos operativos escénicos de la herencia stanislavskiana. Y es por esto que, en Neva, las operaciones dramatúrgicas pretenden confrontar, en su evidencia, las limitaciones que el mismo método -como metonimia del propio teatro- ofrece. En escena, el director plasma las vicisitudes del trabajo actoral -ejercicios respiratorios, olvidos de textos, ensayos infructuosos- que cuestionan la efectividad de los métodos de actuación y se preguntan afectivamente por el sentido del teatro para los sujetos que -como Aleko, Masha y Olga- se encuentran en contextos supeditados por la crisis. Aquí se yergue, en síntesis, un doble gesto de parte de la autoría; el primero descansa en la comprensión de que, para aprehender a cabalidad el presente teatral, es necesario atender a su herencia, y el segundo, que sólo es posible proponer nuevas formas

31 [Cita original]: "Conceiving a method of theatrical composition or construction that tells its own 'plot' through the process of an oral/aural semiosis, the dramaturgy of sound has become constitutive of a theatre that places more emphasis on performance, mise en scène, and the audio-visual architecture of the stage than it does on dramatic text". 
de producción en el entramado cultural, una vez que los aparatos que soportan dicha herencia son puestos en tensión para su desarticulación afectiva, como propone Masha en su última intervención.

Pero, pese a esta resistencia contra las formas teatrales o contra el teatro en sí -como bien consigna el monólogo final-, sus obras siempre finalizan -paradójicamente- en un gesto escénico - muy teatral en varios casos- que termina por completar el sentido de cada uno de sus montajes; en el caso de Neva, una actriz que se precipita al vacío y una estufa que es volteada hacia los espectadores, cegándolos. Es en este gesto donde la comunión entre palabra y escena ocurre, en un último instante escénico, donde la acción y el gesto rodean a la palabra dicha. En este abrazo se funde el teatro de Calderón, un teatro que batalla contra sí mismo y contra la tradición que lo fundamenta, mientras lucha, a su vez, contra la memoria, la historia y el olvido a orillas de un río llamado Neva.

\section{Fuentes consultadas}

Adorno, Theodor W. "Lukács y el equívoco del realismo”. Realismo: ¿Mito, doctrina o tendencia histórica? Buenos Aires: Tiempo Contemporáneo, 1969, pp. 37-85.

Avelar, Idelber. Alegorías de la derrota: La ficción postdictatorial y el trabajo de duelo. Santiago de Chile: Cuarto Propio, 2000.

Baboun Garib, Isabel. "Guillermo Calderón: Tres motivos para una poética casi trágica”. Revista Apuntes, 131, 2009, pp. 20-28.

Bogart, Anne. "Foreword". Theatre E Feeling. Erin Hurley. London: Palgrave Macmillan, 2010, pp. ix-xv.

Bourriaud, Nicolás. Esthétique relationnelle. Dijon: Presses du réel, 1998.

Boston, Jane. "Poetic Text in Contemporary Voice Training: a Repositioning". Voice and Speech Review, vol. 8, núm. 2, 2014, pp. 131-148.

Calderón, Guillermo. "Neva”. Teatro I. Santiago: LOM, 2012, pp. 9-52.

Campos Arancibia, Carolina. "Neva de Guillermo Calderón. Reflexiones en torno a un teatro que se plantea desde, en y como teatro". Tesis de Licenciatura en Lengua y Literatura Hispánicas, Universidad de Chile, 2014.

Clynes, Manfred. Sentics: The Touch of Emotions. New York: Doubledat Anchor, 1989.

Corbalán Herrera, Ana. "Un encuentro de camarín con Trinidad González y Paula Zúñiga, actrices de la Compañía Teatro en el Blanco (Neva y Diciembre), durante sus funciones en el FiBA 2009". Telón de Fondo 10 (diciembre 2009), pp. 1-16, www.telondefondo. org/numeros-anteriores/numero10/articulo/240/un-encuentro-de-camarin-con-trinidad-gonzalez-y-paula-zuniiga-actrices-de-la-companiia-teatro-en-el-blanco-ne- 
va-y-diciembre-durante-sus-funciones-en-el-fiba-2009.html, consultado el 15 de noviembre de 2018.

Dayme, Bunch. Dynamics of the Singing Voice. Austria: Springer Wien New York, 2009.

Goic, Cedomil. Historia y crítica de la literatura hispanoamericana. Volumen 3. Barcelona: Crítica, 1988.

Hurley, Erin. Theatre E Feeling. London: Palgrave Mcmillan, 2010. Consultado el lunes 26 de noviembre de 2018.

Hurtado, María de la Luz. "Prólogo: 1990-2010: De autorías escénico-dramáticas y textuales en la indagación de lo real desde la subjetividad". Antología: Un Siglo de Dramaturgia Chilena. Tomo IV. Eds. María de la Luz Hurtado y Mauricio Barría. Santiago: Publicaciones Comisión Bicentenario, 2010. pp. 11-47.

Hurtado, María de la Luz. "Teatro chileno del siglo xx: de cuerpos mutilados a la representación ficcional/textual de la muerte o de su enigma”. Antología de teatro chileno contemporáneo, editado por María de la Luz Hurtado. La Habana: Casa de las Américas, 2008, pp. 7-48.

Frese Witt, Mary Ann. Metatheater and Modernity. Baroque and Neobaroque. Maryland: Fairleigh Dickinson University Press, 2014.

Lagos, Soledad. “Neva: El río de la Historia”. Revista Apuntes, núm. 129, 2007, pp. 13-18.

Lagos, Soledad. "Neva: Tres actores en escena, una estufa, algunas sillas. Diálogo entre Guillermo Calderón y Soledad Lagos a propósito de Neva". Telón de fondo, núm. 6, 2007, pp. 1-9, www.telondefondo.org/numeros-anteriores/numero6/articulo/124/neva-tres-actores-en-escena-una-estufa-algunas-sillas-dialogo-entre-guillermo-calderon-y-soledad-lagos-a-proposito-de-neva-.html, consultado el 26 de noviembre de 2018.

Larraín, Javiera. "Hacia una poética directorial de Guillermo Calderón: Una cartografía de la palabra escénica”. Tesis de Magister en Artes, Universidad de Chile, 2018.

Nellhaus, Tobin. "Chapter 4. Social Ontology, (Meta)Theatricality, and the History of Communication". Theatre, Communicatin, Critical Realism. New York: Palgrave MacMillan, 2010, pp. 143-181.

Ocampo Guzmán, Antonio. "Introducción". La libertad de la voz natural. El método Linklater. México: UNAM, 2010, pp. 17-35.

Opazo, Cristián. “Clase, de Guillermo Calderón: ensayo de pedagogía chilena”. Revista de Crítica Literaria Latinoamericana, 72 (2010), pp. 17-30.

Oyarzún, Carola. "Entre el teatro y la vida”. Antología: Un Siglo de Dramaturgia Chilena. Tomo IV, editado por María de la Luz Hurtado y Mauricio Barría. Santiago: Publicaciones Comisión Bicentenario, 2010, pp. 303-305.

Oyarzún, Carola \& Opazo, Cristián. "Viajando y buscando eternamente". Revista Theater Der Zeit, núm. Especial (2008), pp. 18-24. 
INVESTIGACIÓNTEATRAL

Revista de artes escénicas y performatividad

Vol. 10, Núm. 15

abril-septiembre 2019
El diálogo afectivo con la tradición

en el teatro chileno reciente

Javiera Larraín George

Ovadija, Mladen. Dramaturgy of Sound in the Avant-Garde and Posdramatic Theatre. Canadá: McGill-Queen's University Press, 2016.

Piña, Juan Andrés. "Verbalidad, política y poesía en el teatro de Guillermo Calderón". Estudios Públicos, núm. 152, 2015, pp. 165-182.

Puchner, Martin. "Introduction". Tragedy and Metatheatre. Essays on Dramatic Form. New York: Holmes \& Meier, 2003, pp. 1-24.

Rodenburg, Patsy. The Right to Speak. Working with the Voice. London: Methuen, 1992.

Sánchez, José A. Prácticas de lo real en la escena contemporánea. Ciudad de México: Paso de Gato, 2013.

Villegas, Juan. Historia multicultural del teatro y las teatralidades en América Latina. Buenos Aires: Galerna, 2005. 